Łukasz RYMANIAK

Barbara SOKOLNICKA

Maciej SIEDLECKI

\title{
Comparative analysis of exhaust emissions from passenger cars and motorcycles
}

The subject of this article is a comparative analysis of exhaust emissions for: $\mathrm{HC}$ (hydrocarbons), $\mathrm{CO}$ (carbon monoxide), $\mathrm{CO}_{2}$ (carbon dioxide), $N O_{x}$ (nitrogen oxides) from a passenger vehicle and a motorcycle in laboratory conditions on a dynamometer station. The first vehicle category was represented by a compression-ignition engine with a displacement volume of $1.3 \mathrm{dm}^{3}$ and a power of $66 \mathrm{~kW}$. The exhaust aftertreatment system included a catalytic converter and a particulate filter. The second category was a motorcycle, equipped with an engine with a displacement of $0.7 \mathrm{dm}^{3}$ and a maximum power of $55 \mathrm{~kW}$. The two-wheeled vehicle was equipped with a three-way catalytic converter. Speeds were modeled on the European type approval test - NEDC (New European Driving Cycle). In order to conduct a comparative analysis of exhaust emissions and fuel consumption from vehicles of different categories, the obtained results were presented in the form of emissions converted into passenger-kilometers $(\mathrm{g} / \mathrm{pkm})$. The research used modern equipment belonging to the PEMS (Portable Emissions Measurement Systems) group of devices. The analyzes carried out enable the decision making on which vehicles have a greater environmental impact due to their exhaust emissions, taking into account the distance and the number of passengers carried.

Key words: combustion engines, passenger car, motorcycle, emission

\section{Introduction}

Globalization, leading towards the integration and interdependence of countries worldwide, not only in the cultural but also in the economic aspect, results in a smoother exchange of goods and their mass consumption. This also applies to the automotive industry. The effect of this phenomenon is excessive degradation of the natural environment by the road transport sector, which is particularly evident in urban agglomeration centers. For example, in Poznań in 2017, the number of newly registered passenger cars reached 425383 , so there were 790 of them per 1000 inhabitants [6]. If the total number of vehicles is taken into account, they exceeded the number of inhabitants by over 24 thousand (Fig. 1). This trend is expected to continue and now this indicator is even larger.

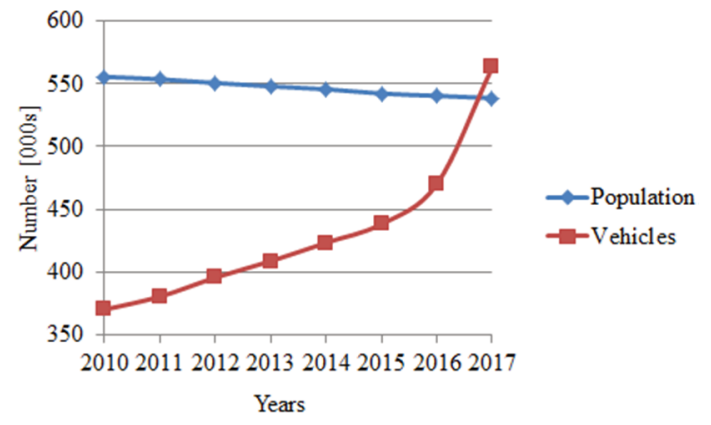

Fig. 1. The number of vehicles registered in Poznań in 2017 and the number of inhabitants [6]

Motor vehicles usually have 3 or 4 seats for passengers. The literature analysis carried out by the authors regarding the rate at which the seats in passenger cars are used allowed to estimate it at 1.2 [3]. The scientific work describing the average number of passengers per car in the Białystok agglomeration on various days of the week was on average 1.54 [2]. This results in exacerbating the phe- nomenon of congestion, resulting in the losses of not only to time and economic losses but also environmental losses. Many studies have shown that the highest exhaust emission values of toxic compounds can be observed for the idle engine operation, where the vehicle uses a significant amount of fuel to overcome its own internal motion resistance, without producing any useful work [5].

An easy solution to problems related to urban mobility in the aspect of the congestion phenomenon is the use of urban single-track vehicles, whose share is significant in densely populated Asian countries. However, in highly developed countries (e.g. European countries), motorcycle units with larger displacement engines enjoy greater popularity, which does not improve the emission rates in the city, also taking into account their limited transport capacity. In addition, the approval rules for two-wheeled vehicles are more liberal compared to other motor vehicles. In Poznań, there is a continuous increase in the number of vehicles of both categories, as shown in Fig. 2 [6].

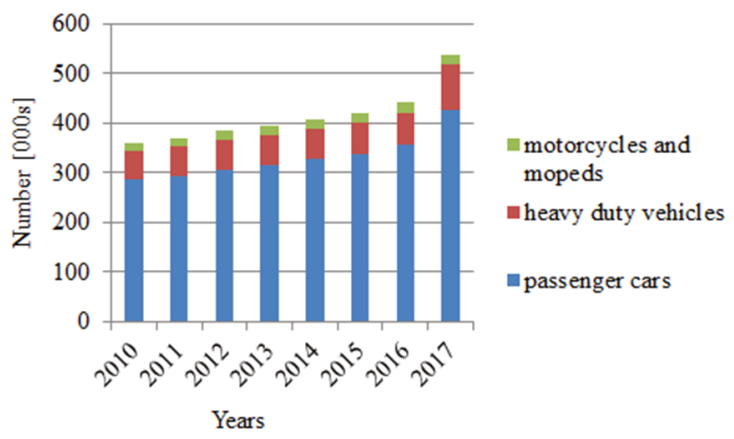

Fig. 2. Vehicles registered in Poznań by type and year [6]

In the light of these problems, this publication is related to considerations regarding the emissivity of various types of vehicles (motorcycles and mopeds and passenger cars) in terms of their transport capacity. For this purpose, the au- 
thors have compared the emissions of toxic compounds and the fuel consumption of a motorcycle and passenger car per one passenger kilometer.

\section{Research metodology}

\subsection{Research objects}

In order to compare the emissivity of different category vehicles, a motorcycle and a passenger car were used for the research. The test object representing the PC group (Passenger Car) was a light vehicle, equipped with a compression-ignition engine, with a displacement of $1.3 \mathrm{dm}^{3}$ and with $66 \mathrm{~kW}$ of power. The exhaust aftertreatment system consisted of a catalytic converter and a particulate filter, the vehicle was manufactured in 2011 and it complied with the Euro 5 emission norms. The second category was represented by a motorcycle equipped with an engine with a displacement of $0.7 \mathrm{dm}^{3}$ and a maximum power of $55 \mathrm{~kW}$. The vehicle was manufactured in 2017 , so it was manufactured to meet the Euro 4 standard. Before the start of the test, its mileage was recorded at $740 \mathrm{~km}$, and the exhaust aftertreatment system consisted of a three-way catalytic converter (TWC).

\subsection{Chassis dynamometer}

The simulation of the NEDC type approval test drive (New European Driving Cycle) for a passenger car was performed on the laboratory engine stand, equipped with a dynamic brake - DynoRoad (Fig. 3).

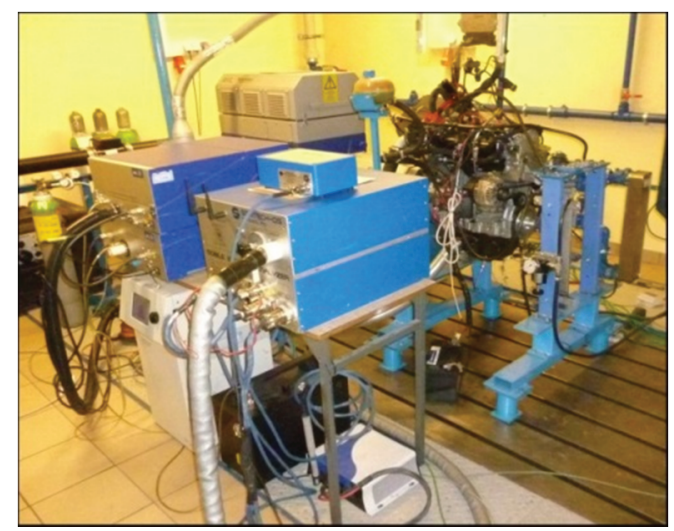

Fig. 3. Dynamometer test bench with the measuring apparatus

This test bench allows to define and input the design features of the tested vehicle such as: mass, type of drive, wheel size, air resistance coefficients or characteristics of the gearbox. The diagram of the procedure is shown in Figure 4. During operation, the combustion engine generates mechanical work converted into electricity by the brake, which after voltage and frequency transformation is transferred to the external network, and excess heat removed by the air cooling system.

Motorcycle tests were carried out using a chassis brake station with a single brake roll, designed for testing twowheeled vehicles. The DYNOmite motorcycle test bench was manufactured by LAND\&Sea [7]. The device can record the vehicle's operational parameters (instantaneous power, torque, speed, acceleration) as well as the distance traveled.

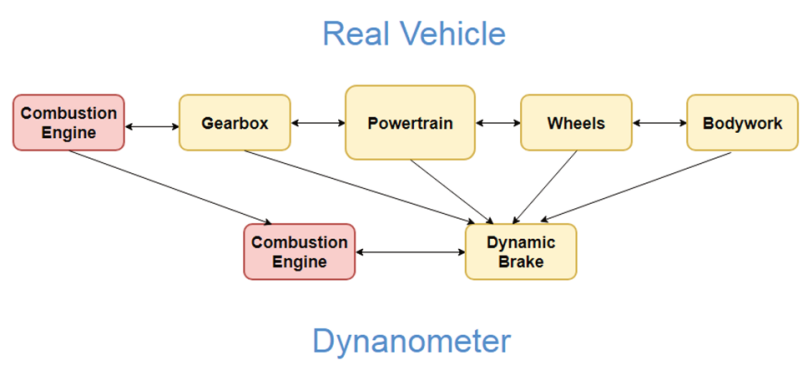

Fig. 4. Diagram of the vehicle simulation process on a test bench

\subsection{Measurement equipment}

The exhaust emissions and fuel consumption measurement were carried out using mobile devices from the PEMS (Portable Emissions Measurement System) group.

SEMTECH DS apparatus (Fig. 5) was used to conduct the exhaust emissions measurement of: $\mathrm{HC}, \mathrm{CO}, \mathrm{CO}_{2}, \mathrm{NO}_{\mathrm{x}}$ from a passenger vehicle. To measure individual exhaust gas compounds, the exhaust sample taken from the mass flow sensor had to pass through a series of analyzers. However, first the sample is subjected to filtration in order to separate out the solid particles. The first analyzer where the sample is sent for testing was the FID (Flame Ionization Detector) analyzer, enabling the determination of hydrocarbon emission. After cooling the exhaust gas to about $4^{\circ} \mathrm{C}$, the sample was then transported to the NDUV (Nondispersive Ultraviolet) analyzer, which determined the content of nitrogen oxides. The content of carbon monoxide and dioxide was determined using the NDIR (Nondispersive Infrared) analyzer. In the last stage, the sample was sent to the electrochemical analyzer, where oxygen content was measured [9].

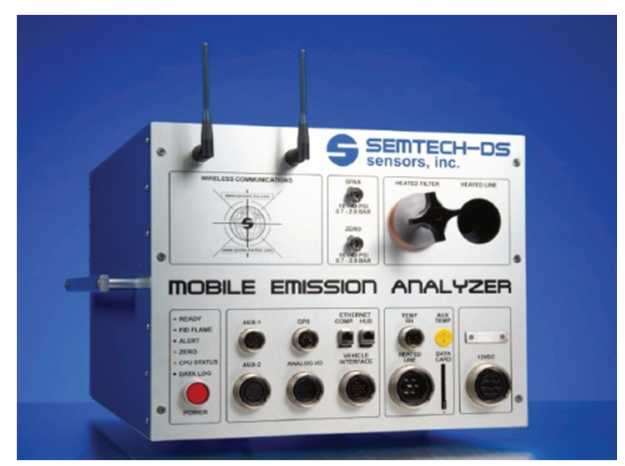

Fig. 5. The SEMTECH DS. exhaust emission analyzer.

Measurements of the above-mentioned harmful exhaust compounds emissions in the case of the four-wheel passenger vehicle were made using the AxionR/S+ device.

The device consists of two sets of analyzers working in parallel. Electrochemical analyzers are used to determine the emission of hydrocarbons, carbon monoxide and dioxide, and oxygen and nitrogen oxide measurements are made using the NDIR analyzer. What's more, the AxionR/S+ device allows the registration and measurement of motor and vehicle data, i.e. acceleration, vehicle speed or intake air temperature [8]. The key advantage of this device, in the aspect of testing of two-wheelers, is its lightweight and compact nature (low weight and small dimensions). Figure 6 shows the test object on the brake station with the measuring apparatus. 
Both measuring instruments were calibrated and zeroed before the tests in order to make the results independent from background noise or ambient impurities.

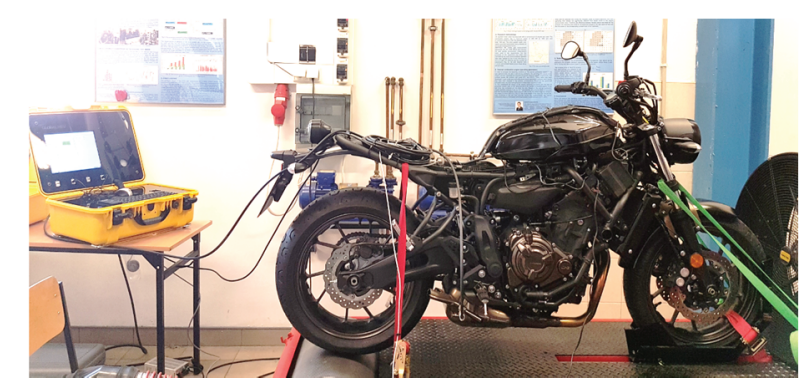

Fig. 6. Picture of the tested motorcycle along with the measuring apparatus on the designated dynamometer

\subsection{NEDC test}

The tests were carried out in accordance with the European NEDC type approval test, dedicated to light motor vehicles. The test consists of two parts: the UDC urban cycle (constituting four ECE 15 tests) and the extra-EUDC cycle. The first test lasted 800 seconds, the second one 400 seconds, each of them was characterized by different maximum value of the vehicle speed (Fig. 7). The total test time is therefore 1200 seconds, and the distance traveled during the test is approximately $11 \mathrm{~km}$.

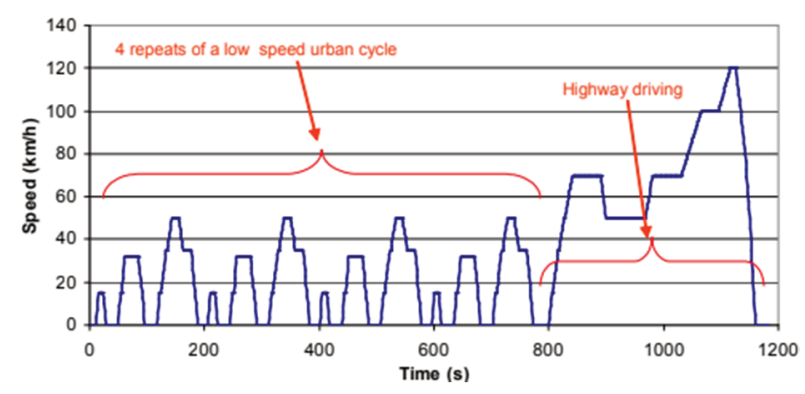

Fig. 7. The NEDC test drive cycle speed profile [1]

\section{Results and analysis}

Data obtained during the NEDC test (the mass of individual exhaust gas compounds, distance and number of passengers) allowed to determine the emission per passenger kilometer for each of the measured exhaust compound. The emission values obtained for various categories of vehicles (motorcycle and passenger car) were used for comparison (Fig. 8). For a light vehicle, the drive was simulated with three passengers, while the NEDC test in the case of the two-wheel vehicle was performed only considering the driver himself. What's more, based on the data concerning the exhaust emission values of carbon containing compounds, the fuel consumption for each of the tested vehicles was calculated using the Carbon Balance method. The comparison showed a significantly higher $\mathrm{CO}_{2}$ and $\mathrm{FC}$ emissions (by $157 \%$ and $151 \%$ respectively) obtained during the motorcycle drive tests. This is mainly due to the less efficient operation of spark-ignition engines (increased unit fuel consumption), in particular when idling and in the case of low engine loads that often occur in the NEDC test. Undoubtedly, differences in fuel consumption and $\mathrm{CO}_{2}$ emissions would be much less significant if the passenger vehicle was only transporting the driver, and if the total fuel consumption and emissions were taken into account. For the motorcycle the emission values of $\mathrm{CO}$ and $\mathrm{NO}_{\mathrm{x}}$ were recorded to be 47 and $92 \%$ lower respectively relative to the passenger car. This outcome was the result of the high exhaust gas aftertreatment system efficiency of the motorcycle, which existed in the form of a three-way catalytic converter (allowing oxidation of carbon monoxide and hydrocarbons with simultaneous reduction of nitrogen oxides). Moreover, the low emission values also resulted from the fact that the vehicle had a lower mileage, in contrast to the passenger car.

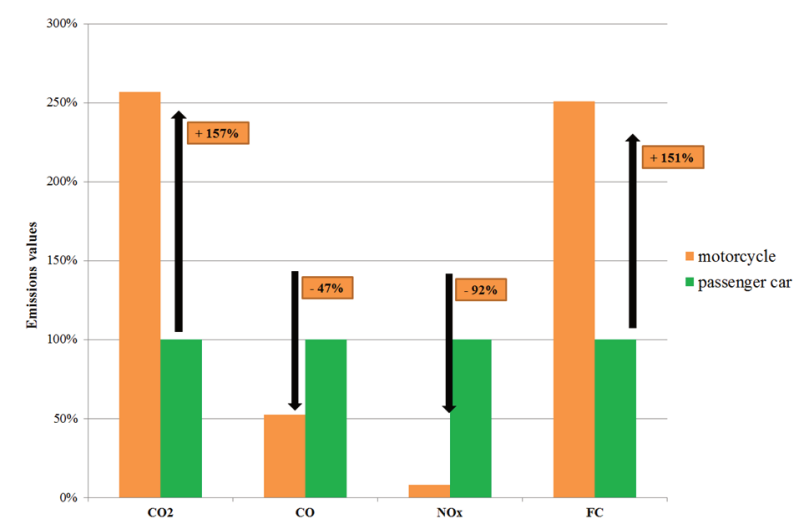

Fig. 8. Exhaust emissions comparison of gaseous compounds and fuel consumption in a passenger-kilometer conversion from the two tested types of vehicles

\section{Conclusions}

The tests and their analysis, which are the subject of this article, were carried out in laboratory conditions at dynamometer stations. The results allowed to formulate conclusions on the impact of particular types of vehicles on emissivity in urban agglomerations. The emission per one passenger kilometer was calculated, and thus the aspect of transport possibilities of particular types of vehicles and their impact on urban emissivity is discussed in this paper. The comparison showed significantly higher $\mathrm{CO}_{2}$ and FC emissions (respectively by $157 \%$ and $151 \%$ ) obtained during the motorcycle tests relative to the passenger car. However, lower values of $\mathrm{CO}$ and $\mathrm{NO}_{\mathrm{x}}$ were recorded for the motorcycle, respectively by 47 and $92 \%$, than for the car. This result can be explained by the high efficiency of the exhaust aftertreatment system in the form of a three-way catalytic converter. This is a positive phenomenon in the aspect of long-term engine operation and exhaust aftertreatment systems, because over time their consumption will adversely affect the ecological indicators. It is estimated that, over time, the differences between the emission values from the analyzed vehicles would gradually decrease.

Poznań is one of the largest cities in Poland, and is thus facing an increasing problem of congestion, lack of parking spaces, air pollution and noise. The solution to these issues is the introduction of the concept of sustainable transport, described in more detail in the White Book of Transport, which assumes that mass transport should prevail in the city urban core, with individual transport prevalent in suburban areas. The main purpose of this document is: "Decrease in the number of cars with conventional drive in urban 
transport by 2030". In addition, policies aimed at reducing the problem of congestion, and thus emissivity in urban agglomeration centers, resulted in the emergence of the concept of carpooling. Carpooling (literally translating "filling the car") means a paid system of traveling together by a private or company vehicle by several people (usually up to five), based around using all the available space in the car during the trip. In the United States of America, such a system is very popular. This publication has shown that the use of full transport capacity has a positive effect on emissions in the urban environment.

\section{Bibliography}

[1] BARLOW, T.J., LATHAM, S., McCRAE, I.S. et al. A reference book of driving cycles for use in the measurement of road vehicle emissions. 2009.

[2] DOBRZYŃSKA, E. Measurement and analysis of the use of cars in city traffic - the case of Bialystok urban area. Economics and Management. 2012, 4, 73-87.

[3] ELLIS, E., CASTLE, A., FARRER K. et al. Great Manchester Transportation Unit. GMTE Report. 2006.

\footnotetext{
Natalia Szymlet, MEng. - Faculty of Transport Engineering, Poznan University of Technology.

e-mail: Natalia.R.Szymlet@doctorate.put.poznan.pl
}

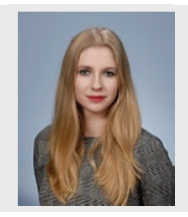

Piotr Lijewski, DSc., DEng. - Faculty of Transport Engineering, Poznan University of Technology. e-mail: Piotr.Lijewski@put.poznan.pl

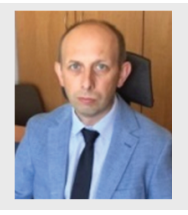

Łukasz Rymaniak, DEng. - Faculty of Transport Engineering, Poznan University of Technology. e-mail: Lukasz.Rymaniak@put.poznan.pl
[4] EUROPEAN COMMISSION. Roadmap to a single European transport area - towards a competitive and resource-efficient transport system. White paper of transport. 2011

[5] PIELECHA, J. Badania emisji zanieczyszczeń silników spalinowych. Wyd. Politechniki Poznańskiej. Poznań 2017.

[6] Satistical Office in Poznań, Poznań statistical bulletin, $1^{\text {st }}$ quarter 2018

[7] www.dynomitedynamometer.com

[8] www.globalmrv.com

[9] www.sensors-inc.com

Barbara Sokolnicka, MEng. - Faculty of Transport Engineering, Poznan University of Technology e-mail: Barbara.D.Sokolnicka@doctorate.put. poznan.pl

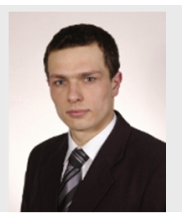

